\title{
Electrochemical Investigation of Bovine Hemoglobin at an Acetylene Black Paste Electrode in the Presence of Sodium Dodecyl Sulfate
}

\author{
Guoqing Zhan, ${ }^{\dagger, 4}$ Chunya $\mathrm{Li}^{+},{ }^{+4 . *}$ and Dengbai $\mathrm{Luo}^{\dagger+4}$ \\ "College of Chemistry and Materials Science, Sonth-Central University for Nationalities, Wuthan 430074, China \\ "E-mail:1ichvchem@163.com \\ ${ }^{*}$ Key Laboratory of Analytical Chemistry of the State Ethnic Affairs Commission, Wuhan 430074, China \\ Received March 31, 2007
}

\begin{abstract}
Electrochemical behaviors of bovine hemoglobin (IIb) at an acetylene black paste electrode based on the enhancement effect of sodium dodecyl sulfate (SDS) were investigated. In the optimal conditions, a very weak reduction peak was observed at an acetylene black paste electrode for hemoglobin in the absence of SDS. IIowever, the reduction peak current increased remarkably after the addition of $4.0 \times 10^{-4} \mathrm{~mol} \mathrm{~L}^{-1} \mathrm{SDS}$, suggesting that SDS exhibits obvious enhancement effect to the determination of hemoglobin. $\mathrm{Nll}$ the experimental parameters, such as $\mathrm{pII}$ value, concentration of SDS, accumulation time and accumulation potential were optimized for hemoglobin analysis. The proposed method possesses high sensitivity (detection limit is $\left.3.0 \times 10^{-9} \mathrm{~mol} \mathrm{~L}-1\right)$, wide linearity $\left(6.0 \times 10^{-9}\right.$ to $\left.6.0 \times 10^{-7} \mathrm{~mol} \mathrm{~L}-1\right)$, rapid response and low cost. Finally, the method was successfully employed to determine hemoglobin in a spiked sample.
\end{abstract}

Key Words : Bovine hemoglobin, Surfactant, Acetylene black, Voltammetry

\section{Introduction}

Hemoglobin $(\mathrm{Hb})$ is a physiologically important globular protein..$^{1-3}$ The physiological function of $\mathrm{Hb}$ is to store and transport dioxygen to the body where it is used in aerobic metabolic pathways. It is also involved in many clinical diseases such as leukemia, anemia, heart diseases, etc. ${ }^{4}$ Therefore, the determination of $\mathrm{Hb}$ is of great importance for clinical diagnosis and physiological research. To date, several means had been reported to determine $\mathrm{Hb}$, including spectrophotometry, ${ }^{5,6}$ fluorimetry, ${ }^{7}$ chemiluminescence ${ }^{8}$ and high performance liquid chromatography. ${ }^{9,10}$ Spectrophotometric or fluorimetric methods for the determination of $\mathrm{Hb}$ were mainly based on its enzymatic activity for the oxidation of chromogens with hydrogen peroxide or other oxidizers, and they have the problems with regard to selectivity, sensitivity and stability of the reagents. Whereas these can be overcome in the electroanalytical detection, consequently, many methods based on electrochemical response of $\mathrm{Hb}$ were constructed for its determination. ${ }^{11-16}$

Compared with cytochrome $\mathrm{c}$, hemoglobin $(\mathrm{Hb})$ usually exhibit more sluggish electron transfer on electrodes because the electroactive section (heme group) in $\mathrm{Hb}$ is much more buried with respect to the protein surface. Therefore, to open the electroactive section of $\mathrm{Hb}$ is a key step for the electrochemical investigation of $\mathrm{Hb}$ at an electrode surface directly. Surfactants are compounds which had a hydrophobic group and a hydrophilic group. They can combine with the protein by the hydrophobic group in solution, and possibly open its electroactive section, while the hydrophilic group might combine with water, which was beneficial to the dissolving of the macromolecules. ${ }^{17}$

In the present paper, we use an anion surfactant SDS to act on $\mathrm{Hb}$ and to investigate the electrochemical behavior of $\mathrm{Hb}$ at an acetylene black paste electrode. The objective of the work is to develop a convenient and sensitive procedure for the determination of $\mathrm{Hb}$ based on the unusual properties of acetylene black coupling with surfactant. Acetylene black, a special type of carbon black, is made by the controlled combustion of acetylene in air under pressure. Due to its excellent electric conductivity, large specific surface area and strong adsorptive ability, acetylene black has been widely used in electrochemistry and electroanalysis. ${ }^{18-22}$ Compared with the other paste electrodes in routine use, acetylene black can significantly improve the electrochemical responses of the analytes, so as to the determining sensitivity can remarkably enhanced. Surfactants are a kind of amphiphilic ions or molecules with a hydrophilic head on one side and a long hydrophobic tail on the other side. They have been widely used in electrochemistry and electroanalysis chemistry field to change the electrical properties of the electrode solution interface and the electrochemical process through adsorption at interfaces via electrostatic interaction and/or hydrophobic interaction. ${ }^{2324}$ In a phosphate buffer $(\mathrm{pH}=6.0), \mathrm{Hb}$ can react with SDS through static interaction. The current response of $\mathrm{Hb}$ at the electrode was enhanced remarkably and a very low detection limit of $3.0 \times 10^{-9} \mathrm{~mol} \mathrm{~L}^{-1}(\mathrm{~S} / \mathrm{N}=3)$ was obtained. Based on these, a simple and sensitive electrochemical method was developed for the determination of $\mathrm{Hb}$. Its successful application in the determination of $\mathrm{Hb}$ in a spiked sample proves that it was a reliable method which was sensitive, simple and low cost.

\section{Experimental Section}

Reagents. Hemoglobin from bovine blood (Shanghai Bo'ao, China) was used without further purification. $1.0 \mathrm{mg}$ $\mathrm{mL}^{-1}$ hemoglobin stock solution was prepared by dissolving 
hemoglobin into $1 / 15 \mathrm{~mol} \mathrm{~L}^{-1}$ phosphate buffer. Working solutions were prepared daily by suitable dilution with phosphate buffer. Sodium dodecyl sulfate (SDS) (Shanghai Reagent Corporation, China) was made into $1.0 \times 10^{-2} \mathrm{~mol}$ $\mathrm{L}^{-1}$ aqueous solutions. Spectroscopic acetylene black powder and paraffin oil were purchased from Shanghai Reagent Corporation, China. Other chemicals were of analyticalreagent grade and used without further purification. All solutions were prepared with redistilled water. All experiments were carried out at room temperature.

Apparatus. All the electrochemical measurements were performed with a $\mathrm{CHI} 660 \mathrm{~A}$ Electrochemical Workstation ( $\mathrm{CH}$ Instrument, USA). A three-electrode system, including acetylene black working electrode ( $3.5 \mathrm{~mm}$ in diameter), a platinum wire counter electrode and a saturated calomel reference electrode (SCE), was employed.

Preparation of the acetylene black paste electrode. The acetylene black paste electrode was prepared by mixing 10.0 mg acetylene black powder and $15.0 \mu \mathrm{L}$ paraffin oil in a small mortar, then, this mixture was homogenized. After that, the paste was pressed into the cavity of the electrode body, and the surface was smoothed against weighing paper. Unless otherwise stated, the paste was carefully removed and another new acetylene black electrode was remade after each measurement.

Determination of hemoglobin. Unless otherwise stated, $1 / 15 \mathrm{~mol} \mathrm{~L}^{-1}$ phosphate buffer containing $4.0 \times 10^{-1} \mathrm{~mol} \mathrm{~L}^{-1}$ SDS was used as the supporting electrolyte for $\mathrm{Hb}$ determination. The accumulation step was carried out at $0.20 \mathrm{~V}$ with $80 \mathrm{~s}$ stirring solution, then the differential pulse voltammograms from 1.00 to $-0.80 \mathrm{~V}$ were recorded after 5 $\mathrm{s}$ qujet time, and finally the peak current at $-0.26 \mathrm{~V}$ was measured.

\section{Results and Discussion}

Electrochemical responses of hemoglobin. Figure I(c) illustrates the cyclic voltammogram (CV) of a acetylene black electrode in the phosphate buffer containing $4.0 \times 10^{-4}$ mol L ${ }^{-1}$ SDS. No redox peak was observed in the potential range, suggesting that SDS is an electrochemically inactive compound. As shown in Figure 1(b), however, a reduction peak which was not well-defined could be seen at about $0.56 \mathrm{~V}$ without the effect of the surfactant. Figure 1 (a) shows the cyclic voltammogram obtained at the acetylene black electrode for $7.0 \times 10^{-7} \mathrm{~mol} \mathrm{~L}^{-1}$ hemoglobin after the addition of SDS. We observed that $\mathrm{Hb}$ would give a much larger current response if we added $4.0 \times 10^{-4} \mathrm{~mol} \mathrm{~L}^{-1}$ SDS to the phosphate buffer solution containing $\mathrm{Hb}$. The $\mathrm{CV}$ curve show that $\mathrm{Hb}$ could present a satisfying result after it was acted on by SDS. Because of the effect of the surfactant, the peak current of the protein increase greatly and the shape of the reduction peak was also improved.

Differential pulse voltammetry was further applied for the electrochemical investigation of $\mathrm{Hb}$ at the acetylene black electrode in the presence of SDS. From the voltammograms of Figure $2(\mathrm{c})$ and $(\mathrm{d})$, in the potential range from $0.60 \mathrm{~V}$ to -

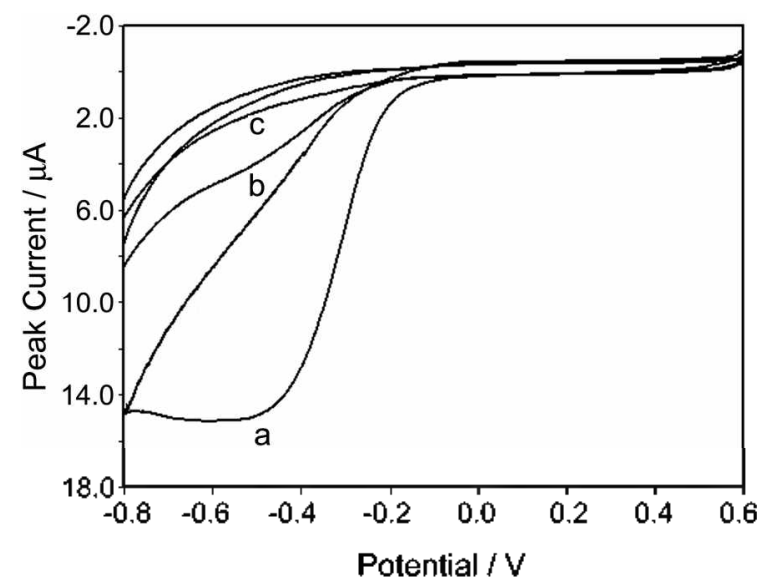

Figure 1. Cyclic voltamunetric response of the acetylene black electrode in the presence of (a) $7.0 \times 10^{-7} \mathrm{~mol} \mathrm{~L}^{-1}$ hemoglobin and $4.0 \times 10^{-4} \mathrm{~mol} \mathrm{~L}^{-1} \mathrm{SDS}$; (b) $7.0 \times 10^{-7} \mathrm{~mol} \mathrm{~L}^{-1}$ hemoglobin; (c) 4.0 $\times 10^{-4} \mathrm{~mol} \mathrm{~L}^{-1} \mathrm{SDS}$.

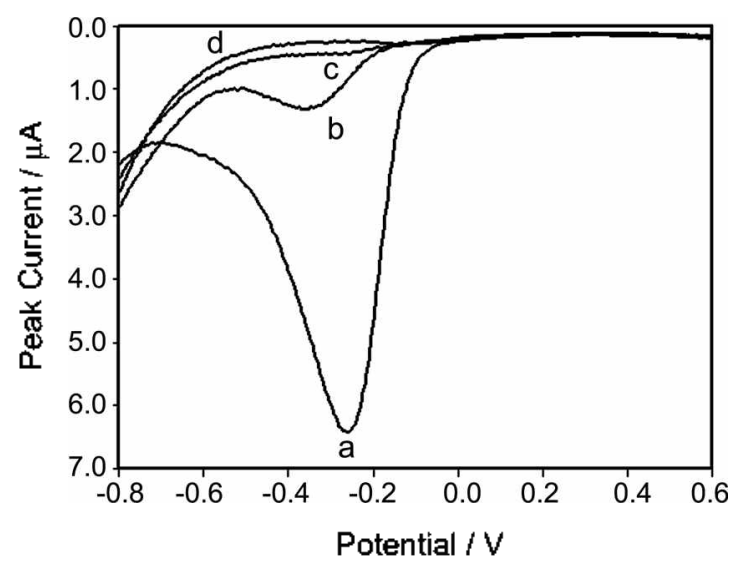

Figure 2. Differential pulse voltammograms for the acetylene black electrode in the presence (a) $3.0 \times 10^{-7} \mathrm{~mol} \mathrm{~L}^{-1}$ hemoglobin and $4.0 \times 10^{-4} \mathrm{~mol} \mathrm{~L}^{-1}$ SDS; (b) $3.0 \times 10^{-7} \mathrm{~mol} \mathrm{~L}^{-1}$ hemoglobin; (c) $4.0 \times 10^{-1} \mathrm{~mol} \mathrm{~L}^{-1}$ SDS and (d) phosphate buffer.

$0.80 \mathrm{~V}$, no reduction peaks were observed at the electrode in $1 / 15 \mathrm{~mol} \mathrm{~L}^{-1}$ phosphate buffer in the presence and absence of SDS. However, when $3.0 \times 10^{-7} \mathrm{~mol} \mathrm{~L}^{-1} \mathrm{Hb}$ was added, an obvious reduction peak can be observed at $-0.36 \mathrm{~V}$ without the effect of SDS. But after the addition of SDS, perfect peak of $\mathrm{Hb}$ could be obtained at $-0.26 \mathrm{~V}$. The positive shift of the peak potential suggested that the reduction process of $\mathrm{Hb}$ at the acetylene black electrode was facilitated by the added anionic surfactant SDS. This not only proves once again that SDS could make $\mathrm{Hb}$ give a gratifying voltammetric response, but also means the possibility of microanalysis for $\mathrm{Hb}$.

Effect of $\mathrm{pH}$ value. The electrochemical responses $\mathrm{Hb}$ at the acetylene black electrode showed remarkable dependence on the $\mathrm{pH}$ value of supporting electrolyte. Figure 3 is the voltammetric measurement results for $0.3 \mu \mathrm{mol} \mathrm{L}^{-1} \mathrm{Hb}$ in $1 / 15 \mathrm{~mol} \mathrm{~L}^{-1}$ phosphate buffer solutions at different $\mathrm{pH}$ values. It could be observed that, as the $\mathrm{pH}$ value increased in the range of 4.5-5.8, the peak currents for $\mathrm{Hb}$ increased while the peak potentials shifted negatively. The maximum 


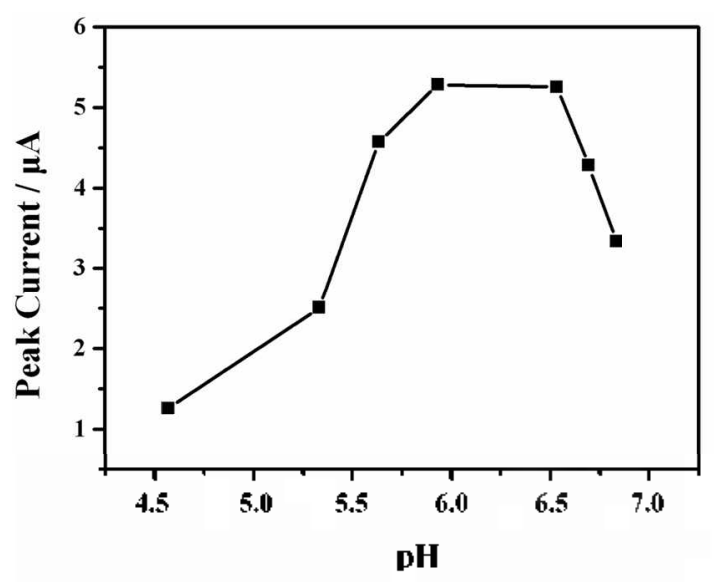

Figure 3. Effect of $\mathrm{pH}$ on the peak current response of $3.0 \times 10^{-7}$ mol $\mathrm{L}^{-1}$ hemoglobin in the presence of $4.0 \times 10^{-4} \mathrm{~mol} \mathrm{~L}-1$ SDS.

peak current response can be obtained in $\mathrm{pH}$ range from 5.8 to 6.5 . When the $\mathrm{pH}$ value was higher than 6.5 , the peak current decreased rapidly. Therefore, $\mathrm{pH} 6.0$ was selected for the electrochemical investigation of $\mathrm{Hb}$ in the further experiments.

Influence of $\mathrm{pH}$ on the electrochemical behavior of $\mathrm{Hb}$ at the acetylene black past electrode coupling with SDS was due to the electrostatic interaction between $\mathrm{Hb}$ and SDS. The isoelectric point (pI) of bovine hemoglobin is known to be 7.1. In a strong acid solution, the amount of protonated amino acid residues will increase. However, the electrostatic force of $-\mathrm{SO}_{3}{ }^{2-}$ will be decrease, so as to a few amount of $\mathrm{Hb}$-SDS aggregates can be formed and adsorbed to the electrode surface. When $\mathrm{pH}$ values higher than the protein $\mathrm{pI}$ value $(\mathrm{pI}=7.1)$ for bovine hemoglobin, there is a decrease of available cationic sites and that would reduce the electrostatic contribution of SDS. According to literature reports both ionic as well as hydrophobic interactions between SDS and heme proteins at about $\mathrm{pH} 7.0$ might be important for the formation of a complex equilibrium involving several species. ${ }^{25}$ Hydrophobic interactions promoted by SDS may be an important factor for the adsorption of $\mathrm{Hb}$ to the electrode surface. Therefore, a maximum current response can be obtained at $\mathrm{pH}$ range from 5.8 to 6.5 . A similar phenomenon can be observed in the absence of SDS, indicating that the electrode process is not changed after the addition of SDS.

Effect of SDS concentration. In addition, the effects of SDS concentration on the reduction of $\mathrm{Hb}$ were depicted in Figure 4. The reduction peak current increased with the increase of SDS concentration when SDS concentration was lower than $4.0 \times 10^{-1} \mathrm{~mol} \mathrm{~L}^{-1}$. A maximum current response was obtained in the presence of $4.0 \times 10^{-4} \mathrm{~mol} \mathrm{~L}^{-1}$ SDS. However, with the further increase of SDS concentration, the reduction peak current decreased. It is due to the formation of SDS layer on the electrode surface, and the electron transfer between $\mathrm{Hb}$ and the electrode was blocked. To sum up, $4.0 \times 10^{-4} \mathrm{~mol} \mathrm{~L}^{-1}$ SDS can more effectively improve the reduction peak current of $\mathrm{Hb}$ at the carbon electrode. Moreover, the effect of different surfactants on the

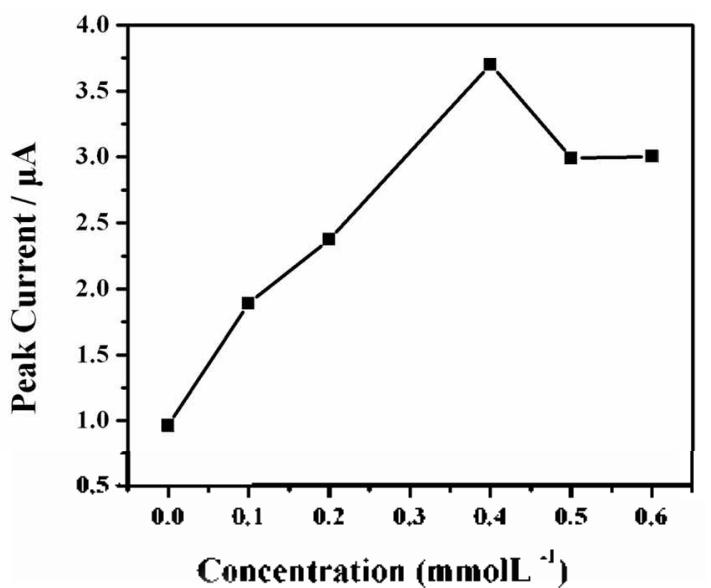

Figure 4. Dependence of peak current of $2.0 \times 10^{-7} \mathrm{~mol} \mathrm{\textrm {L } ^ { - 1 }}$ hemoglobin on the concentration of SDS.

current response of $\mathrm{Hb}$ at the acetylene black electrode was also investigated. The results indicated that neutral surfactants (trition X-100) has almost no influence on the electrochemical response of $\mathrm{Hb}$, cationic surfactants such as hexadecyl trimethylammonium bromide (CTAB) and cetyl pyridine bromide (CPB) can improve its current response on a certain degree especially in a base solution. Whereas, anionic surfactant both sodium dodecyl sulfate (SDS) and sodium dodecyl benzene sulfonate (SDBS) can remarkably enhance the current response of $\mathrm{Hb}$ in acid solution. The enhancement of peak current in the presence of SDS is larger than that in the presence of SDBS, thus, SDS is chosen for the further determination of $\mathrm{Hb}$. Above results indicated that the enhancement of the peak current mainly come from the increase of the amount of surface adsorption via electrostatic and/or hydrophobic interaction.

Effect of accumulation conditions. Because accumulation can improve the amount of $\mathrm{Hb}$ on the electrode surface, then obviously improve the determining sensitivity. So, the two main parameters of accumulation step-accumulation potential and time were examined, respectively. As shown in Figure 5(A), when the accumulation potential shifts from 0.70 to $0.20 \mathrm{~V}$, the peak current of $\mathrm{Hb}$ increases slightly and a maximum current response was obtained at about $0.20 \mathrm{~V}$. With further increase of the accumulation potential from $0.20 \mathrm{~V}$ to $0.40 \mathrm{~V}$, the peak current varied slightly. That is to say, the further increase of accumulation potential has no visible influence on the adsorption of $\mathrm{Hb}$ on the surface of the acetylene black electrode. Therefore, the accumulation was carried out at $0.20 \mathrm{~V}$ with the solution stirring. The influence of accumulation time ranged from 0 to $90 \mathrm{~s}$ on the reduction peak current of $\mathrm{Hb}$ at the acetylene black electrode was shown in Figure 5(B). The peak current increases with extending the accumulation time in the range $0-60 \mathrm{~s}$. Under the same experimental conditions, the longer the accumulation time, the more $\mathrm{Hb}$ was adsorbed to the electrode surface. Afterward, the peak current tends to be stable with further increasing accumulation time from $60 \mathrm{~s}$ to $90 \mathrm{~s}$. This may be attributed to the saturated adsorption of 

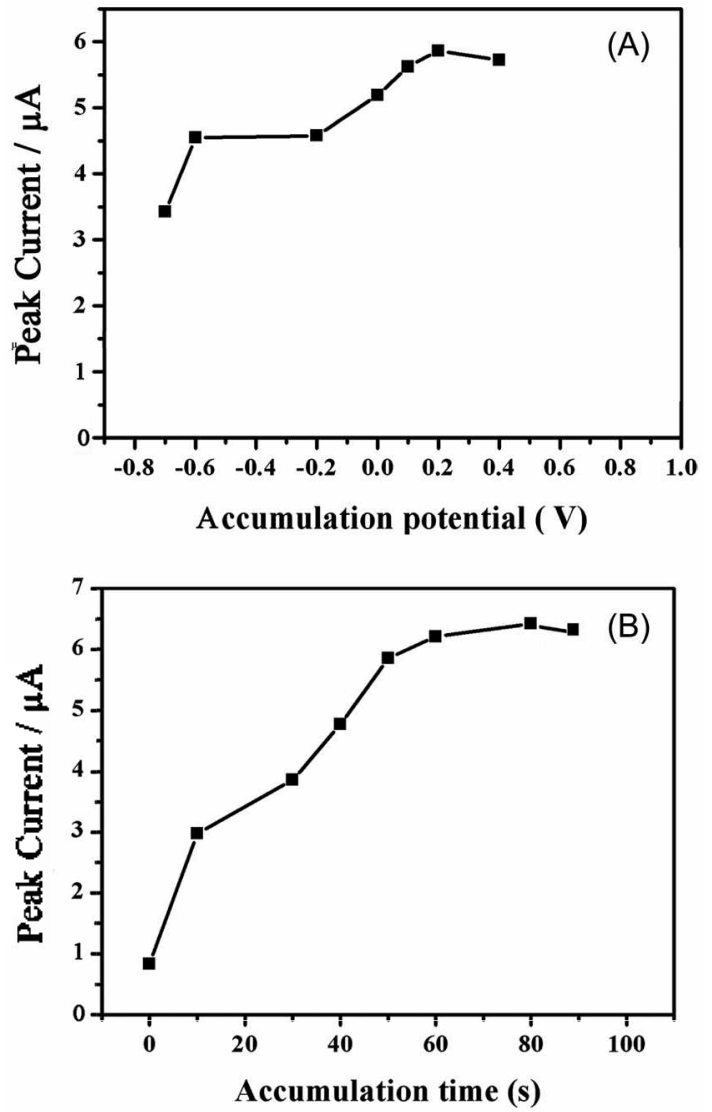

Figure 5. Dependence of peak current on the accumulation potential (A) and the accumulation time (B).

$\mathrm{Hb}$ at the electrode surface. Therefore, the optimal accumulation time of $80 \mathrm{~s}$ was employed in the further experiment.

Calibration curve. The calibration curve for the determination of $\mathrm{Hb}$ in the presence of SDS in $1 / 15 \mathrm{~mol} \mathrm{~L}^{-1}$ at the acetylene black electrode under optimal working conditions was characterized by DPV and presented as Figure 6. The reduction peak current was linearly related to the concentration of $\mathrm{Hb}$ in the range of $6.0 \times 10^{-9}$ to $6.0 \times 10^{-7} \mathrm{~mol} \mathrm{~L}^{-1}$. The linear regression equation can be described as following: $\operatorname{Ip}(\mu \mathrm{A})=14.2814 \mathrm{C}\left(\mu \mathrm{mol} \cdot \cdot^{-1}\right)+0.7547(r=0.9991)$. A detection limit of $3.0 \times 10^{-9} \mathrm{~mol} \mathrm{~L}^{-1}$ (based on $\mathrm{S} / \mathrm{N}=3$ ) was obtained with $80 \mathrm{~s}$ accumulation time. With the same electrode which was rinsed and then polished on a piece of weighting paper to remove the previous deposits on the surface of the electrode, the relative standard deviation (R.S.D.) is $2.46 \%$ for 7 times parallel detections of $3.0 \times 10^{-7}$

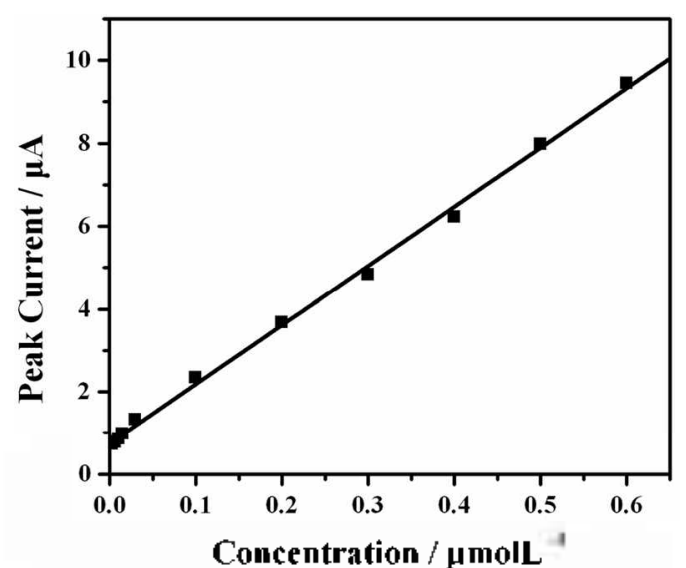

Figure 6. Calibration curve for the determination of hemoglobin.

Table 1. Interferences of some species on the current response of $3.0 \times 10^{-7} \mathrm{~mol} \mathrm{~L}^{-1}$ hemoglobin

\begin{tabular}{lcc}
\hline Interferences & $\begin{array}{c}\text { Concentration/ } \\
\left(\mu \mathrm{mol} \cdot \mathrm{L}^{-1}\right)\end{array}$ & $\begin{array}{c}\text { Peak current change } \\
(\%)\end{array}$ \\
\hline BSA & 0.15 & 7.6 \\
proline & 46.5 & 1.3 \\
arginine & 15.7 & 3.8 \\
L-threonine & 83.9 & 7.4 \\
L-histidine & 6.5 & -5.1 \\
serine & 19.0 & 0.61 \\
tryptophan & 97.9 & 0.26 \\
valine & 18.2 & 5.2 \\
alanine & 24.3 & 2.8 \\
glycin & 17.1 & 3.7 \\
leucine & 27.2 & 4.2 \\
Co & $2^{2-}$ & -7.1 \\
$\mathrm{Zn}^{-2}$ & 0.15 & -1.0 \\
$\mathrm{~Pb}^{2-}$ & 17.9 & -1.0 \\
$\mathrm{Ni}^{2-}$ & 4.8 & -1.0 \\
\hline
\end{tabular}

$\mathrm{mol} / \mathrm{L} \mathrm{Hb}$, suggesting satisfactory reproducibility.

Interference. Under optimal experimental conditions, the interferences of some metal ions, amino acids and bovine serum albumin (BSA) have been evaluated. The peak currents of $3.0 \times 10^{-7} \mathrm{~mol} \mathrm{~L} \mathrm{~L}^{-1} \mathrm{Hb}$ in the absence and presence of foreign species were measured by DPV, respectively, and the error was consequently obtained. The results are listed in Table I. It was found that praline, arginine, serine, tryptophan, alanine, glycin, leucine, $\mathrm{Zn}^{2+}, \mathrm{Pb}^{2+}$ and $\mathrm{Ni}^{2+}$ almost do not interfere with the reduction current response of $\mathrm{Hb}$

Table 2. Determination of hemoglobin in a spiked sample

\begin{tabular}{cccccc}
\hline sample & $\begin{array}{c}\text { Spiked concentration } \\
\left(\text { mol } \cdot \mathrm{L}^{-1}\right)\end{array}$ & Co-existing species & $\begin{array}{c}\text { Found } \\
\left(\mathrm{mol} \cdot \mathrm{L}^{-1}\right)\end{array}$ & $\begin{array}{c}\text { Recovery } \\
(\%)\end{array}$ & RSD \\
\hline 1 & $1.50 \times 10^{-7}$ & L-threonine, L-histidine, & $1.45 \times 10^{-7}$ & 96.7 & \\
2 & $1.50 * 10^{-7}$ & tryptophan, praline, arginine, & $1.48 \times 10^{-7}$ & 98.7 & 2.22 \\
3 & $1.50 * 10^{-7}$ & $\mathrm{BSA}, \mathrm{Co}^{2-}, \mathrm{Cd}^{2-}, \mathrm{Ni}^{2-}, \mathrm{Zn}^{2}$ & $1.53 \times 10^{-7}$ & 99.3 & 102.0 \\
4 & $1.50 * 10^{-7}$ & & 1.0 & \\
\hline
\end{tabular}

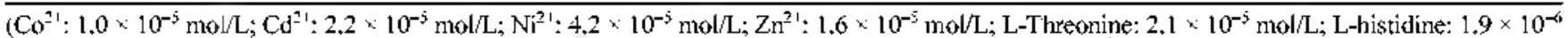
mol/L; tryptophan: $1.0 \times 10^{-6} \mathrm{~mol} / \mathrm{L}$; proline: $2.3 \times 10^{-5} \mathrm{~mol} / \mathrm{L}$; arginine: $2.9 \times 10^{-6} \mathrm{~mol} / \mathrm{L} ; \mathrm{BSA}: 3.7 \times 10^{-8} \mathrm{~mol} / \mathrm{L}$ ) 
(signal change below 5.0\%). However, BSA, L-threonine, L-histidine, valine and $\mathrm{Co}^{2+}$ have relatively obvious interference on the detemination of $\mathrm{Hb}$.

Determiantion of $\mathbf{H b}$ in a spiked sample. In order to test the practical applicability of the proposed method, the concentration of $\mathrm{Hb}$ in a spiked sample was determined, and the results are shown in Table 2 . The relative standard deviation for four-time parallel detections was $2.22 \%$. In addition, the recovery on the basis of the above method was in the range of $96.7-102.0 \%$. The result indicates that the determination of $\mathrm{Hb}$ at the acetylene black electrode using SDS as enhancing element is effective and sensitive.

\section{Conclusion}

In the present paper, electrochemical behaviors of $\mathrm{Hb}$ in the absence and presence of SDS at the acetylene black electrode were investigated. The results indicated that the electrochemical responses of $\mathrm{Hb}$ were facilitated by the anion surfactant SDS. The experimental parameters which would affect the reduction peak current response of $\mathrm{Hb}$ have been optimized. Advantages of this method are simple, sensitive and accurate, which were demonstrated by its application in the determination of $\mathrm{Hb}$ in a spiked sample.

Acknowledgement. The author gratefully acknowledges the financial support from the Nature Science Foundation of South-Central University for Nationalities (No. Y2205014 and No. YZY06011).

\section{References}

1. Amdt, M. H. L.; de Oliveira, C. L. P.; Régis, W. C. B.; Torriani, I. L.; Santoro, M. M. Biopoly: 2003, 69, 470.
2. Bonaventura, J.; Bonaventura, C.; Sullivan, B. J. Experiment. Zool. 1975, 194, 155 .

3. Cordone, L.; Cupane, A.; Sandro, L. Biopoh: 1983, 22, 1677.

4. Wells, C. W.; Lewis, S.; Barton, J. R.; Corbett, S. Inflamm. Bowel Dis, 2006, $12,123$.

5. Ruan, P.; Huang, Y. X.; Li, D. Spectrosc. Spect, Anal. 2005, 25, 1121 .

6. Cruz-Landeira, A.; Bal, M. J.; Quintela, O.; Lopez-Rivadulla, M. J. Anal. Toxic. 2002, 6,67.

7. Yang, X. F.; Guo, X. Q.; Li, H. Talanta 2003, 61,439.

8. Quickenden, T. I.; Cooper, P. D. Luminescence 2001, 16, 251.

9. van Bommel, M. R, de Jong, A. P. J. M.; Tjaden, U. R.; Irth, H,; van der Greef, J. J. Chronatogr. A 2000, 886, 19.

10. Huisman, T. H. J. Antal. Chim. Acta 1997, 352, 187.

11. D'Antonio, E. L.; Rickard, L. H. Abstrocts of Papers of the American Chemical Society 2004, 227, U612-U612 755-Ched Part I.

12. Bao, X.; Zhu, Z.; Li, N. Q.; Chen, J. Talanta 2001, 54, 59l.

13. Liu. M.; Shi, G.; Zhang. L.; Cheng, Y.; Jin. L. Electrochen. Conmun 2006, 8, 305 .

14. Zhang, C. L.; Liu, M. C.; Li, P.; Xian, Y. Z.; Cheng, Y. X.; Zhang, F. F.; Wang, X. L.; Jin, L. T. Chin. J. Chem. 2005, 23, I44.

15. Fan, C. H.; Li, G. X.; Zhuang, Y, Electroanal. 2000, 12, 205.

16. Bretl, C. M. A.; Inzelt, G.; Kertesz, V. Anal. Chim. Acta 1999, 385 , 119.

17. Li, G. X.; Chen, H. Y.; Zhu, D. X. J. Inorg, Biochem. 1996, 63 , 207.

18. Yang, X. F.; Zhang, H. J. Food Chem. 2007, 102, 1223.

19. Yang, X. F.; Wang, F,; Hu, S. S. Colloids Surf. B: Biointerfaces $2007,54,60$.

20. Sun, D.; Zhang, H. J. Water Res. 2006, 40, 3069.

21. Li, G.; Ji, Z. M.; Wu, K. B. Antal. Chim. Acta 2006, 577 , 178 .

22. Zhang, H. J. Bioelectrochem, 2006, 68, 197.

23. Xie, P. P.; Chen, X. X.; Wang, F.; Hu, C. G.; Hu, S. S. Colloids Surf. B: Biointerfaces 2006, 48, 17 .

24. Li, C. Y. Colloids Strf. B: Biointerfaces $2007,55,77$.

25. Chattopadhyay, K.; Mazumdar, S. Biochem. 2003, 42, 14606. 